\title{
Studying potential PKC $\delta$ loss of function mutation and its downstream effects in gastric cancer progression
}

\author{
Xingyu Guo ${ }^{1}$ \\ ${ }^{1}$ RMIT, Melbourne, Australia
}

\begin{abstract}
PKC isozymes are involved in the modulation of cellular pathways related with tumor progression, acting as a suppressor or promoter. In cancer cells, PKCs are mutated, and most common type is loss of function. This paper focuses on the effect of PKC $\delta$ mutation in gastric cancer. LOF mutation occurs throughout catalytic and kinase domains of $\mathrm{PKC} \delta$, disrupting activation and function of kinase. In catalytic domain, there are various potential mutation targets, such as binding groove and zinc finger. Mutation residues detected in the kinase domain, such as DFG and APE motifs, can alter catalytic function, causing interruption of activation. Also, a critical region, called hinge region, modulates caspase- 3 dependent cleavage, and such tyrosine mutation in this region reduces cleavage activity, inhibiting fully activation of kinase. Importantly, LOF mutation affects cellular activity of downstream protein, p53, through inhibiting transcription, localization, and phosphorylation. For instance, C1 domain mutant suppresses binding capacity with p53, reducing transcription of p53. Disruption of cellular component, tight junction, assembling related to PKC mutation. As identified, $\mathrm{PKC} \delta$ correlates with ZO-1, and LOF mutation prevent translocation of ZO-1 to TJ area, leading to errors in $\mathrm{TJ}$ assembling, promoting tumor invasion.
\end{abstract}

\section{Introduction}

Protein Kinase $\mathrm{C}$ delta $(\mathrm{PKC} \delta)$ is important in suppressing gastric cancer and a treatment target of several anti-cancer drugs. But in gastric cancer cells, PKC $\delta$ is commonly loss of function (LOF) mutated [1]. The mutation may cause the failure of treatments and understanding the effects of mutation on pathways related to cancers will provide more information for studying new treatment strategies. Also, the effect of PKC $\delta$ mutation on regulatory pathways or proteins involved in stomach cancer is rarely known. So this report will investigate potential mutation residues of PKC $\delta$, and how LOF mutation affects pathways and association with other proteins related to gastric cancer.

$\mathrm{PKC}$ is a kinases family that functions through the phosphorylation of serine and threonine residues and identified as the molecule which provides signal and links multiple processes to diseases, such as cardiovascular dysfunctions and cancer [2]. PKC family proteins are divided into three groups, including conventional (cPKC $\alpha, \beta$ and $\gamma$ ), novel (nPKC $\delta, \varepsilon, \eta$ and $\theta$ ) and atypical (aPKC $\zeta, 1$ and $\lambda$ ) [3]. All PKC proteins, basically, have regulatory, kinase domain, and a hinge region, and can be activated by diacylglycerol (DAG) (Figure 1). However, PKC isozymes have different characteristics based on the structure and activation mechanisms. The characterize of conventional class differing from others is that the $\mathrm{C} 2$ domain contains a $\mathrm{Ca}^{2+}$ binding site, and the only cPKC can be activated by $\mathrm{Ca}^{2+}$. nPKC shares a similar structure with conventional

\footnotetext{
Xingyu.guo93@gmail.com
}

type, except that the $\mathrm{C} 2$ domain cannot bind to $\mathrm{Ca}^{2+}$ and no functional groups that mediate the binding of $\mathrm{Ca}^{2+}$. The newly identified and the least understood type is aPKC, which only has a $\mathrm{C} 1$ domain and does not interact with phorbol ester [4]. Phorbol ester, a tumor promoter, can activate PKC family, except aPKC, and is not easily metabolized.

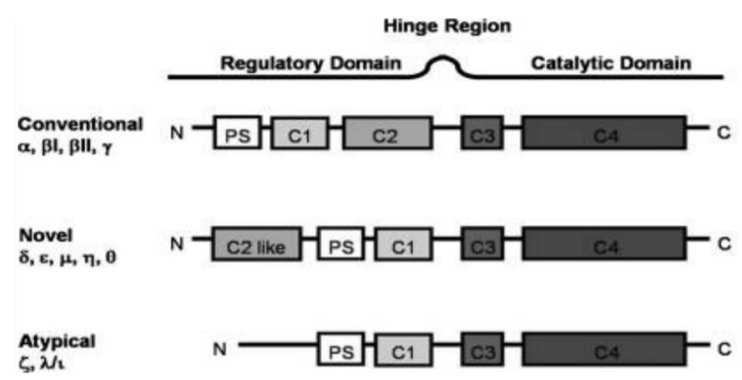

Figure 1. PKC family proteins have regulatory and catalytic domain [5].

In cancer cells, PKC family is involved in multiple mechanisms, including apoptosis, proliferation, and survival, importantly, affecting proteins associated with cancer progression and metastasis. Gastric cancer remains a high incidence and motility rate around the world, and in carcinoma and adenocarcinoma cells, PKCs are often dysregulated and mutated, additionally, mutation of $\mathrm{nPKC}$ is most commonly detected [1].

$\mathrm{PKC} \delta$ is considered as a tumor suppressor because of its essential role in the pro-apoptotic pathway and inhibiting proliferation [6]. In certain cancer types, $\delta$ 
isozyme certainly suppress tumor growth and proliferation. For instance, in epidermoid carcinomas, the activation of $\mathrm{PKC} \delta$ down-regulates tumorgenicity by inducing apoptosis, and overexpression of $\mathrm{PKC} \delta$ suppress tumor phenotypes of colonic cancer [7], indicating the role of $\mathrm{PKC} \delta$ in suppressing cancer progression. However, PKC $\delta$ has also been shown the function of promoting survival of some cancer types, such as lung cancer. Clark et al. proved that instead of wild type $\mathrm{PKC} \delta, \mathrm{PKC} \delta$-dead mutation enhanced apoptosis of non-small cell lung cancer (NSCLC) cells, indicating that $\mathrm{PKC} \delta$ was related to survival of NSCLC cells [8]. Taken together, $\mathrm{PKC} \delta$ can act as tumor promoter to up-regulate survival of cancer cells.

For gastric cancer, PKC $\delta$ is supposed to be the tumor suppressor. As, firstly, stomach cancer cells with up-regulated PKC $\delta$ have limited survival rate [9]. Also, PKC $\delta$ is involved in pathways induced by other tumor suppressor proteins, such as p53, and exhibits an essential regulatory role. The function of p53 highly depends on phosphorylation of certain residues, which is mediated by $\mathrm{PKC} \delta$. For instance, $\mathrm{PKC} \delta$ induces the phosphorylation of p53 on Serine 46, promoting cell death [10]. Overall, considering the effect of PKC $\delta$ on proteins associated with cancer, $\delta$ isozyme is a tumor suppressor for gastric cancer.

Mutation is often occurred in cancers, causing disruption of normal cellular functions. Now, over 1000 mutations found in all PKC isozyme are reported and occur throughout various domains. Also, various PKC isozymes has higher mutation rate in certain cancer types, such as PKC $\delta$ is commonly mutated in stomach cancer [1]. Newton revealed that most common mutation type for PKC in cancer cells was loss of function (LOF) [6]. Based on data from cBioPortal, all already documented mutations of $\mathrm{PKC} \delta$ detected in stomach cancer may cause functionally lost in cancer cells [11].

\section{Potential mutation sites of PKC $\delta$ in gastric caner}

\subsection{Regulatory domain}

Similar to other PKC proteins except atypical type, regulatory region of $\mathrm{PKC} \delta$ is composed of $\mathrm{Cl}$ and C2-like domain. $\mathrm{C} 1$ region has $\mathrm{C} 1 \mathrm{~A}$ and $\mathrm{C} 1 \mathrm{~B}$ components. In the $\mathrm{C} 1 \mathrm{~B}$ domain, there is a binding groove formed near two beta sheets. PMA will bind to this groove, and if no PMA binding, the hydrogen bond bridge will be generated between strands [12]. Also, C1B has two zinc fingers, controlling the affinity for substrate binding and the structure of protein [13]. PKC $\delta$ has a C2-like domain, as it does not have the calcium binding site, indicating that in the activation mechanism, $\mathrm{PKC} \delta$ does not require the calcium (Figure 1) [5].

In cancer cells, for $\mathrm{PKC} \delta$, main mutation type is loss of function, especially in gastric cancer cells [1]. The function of $\mathrm{C} 1$ domain is phosphorylation or binding to the substrate which could active the protein, so the mutation should be occurred in residues which can regulate the action of the protein. Although fewer research examines mutation sies of $\mathrm{PKC} \delta$ in gastric cancer, other classical or novel PKC proteins could be used to estimate the mutated sites as they share a similar structure and function for the $\mathrm{C} 1$ domain.

A research identified the structural alteration in PKC alpha, which shares the similar structure of $\mathrm{C} 1$ domain with PKC $\delta$. The mutation residues are Trp 58 and His 75 located on the binding groove and zinc finger, disrupting the DAG binding and the phosphorylation of protein [1]. Although PKC $\delta$ does not have same residues at position 58 and 75 with alpha isozyme, mutation sites are supposed to be around the binding groove and zinc fingers.

Furthermore, tyrosine residues in the regulatory domain can regulate the nuclear translocation of PKC $\delta$. Nuclear accumulation is essential for the apoptosis induced by $\mathrm{PKC} \delta$. In non-apoptotic cells, the kinase predominantly sits in the cytoplasm, and after the induction of apoptosis, PKC $\delta$ is translocated to nucleus. The finding proves that the phosphorylation of Y-64 and -155 is critical for translocation. Humphries et al. generated PKC 8 Y64F and PKC 8 Y $155 \mathrm{~F}$ mutants, and in cells with these mutants, PKC $\delta$ could not be detected in nucleus, indicating that both residues regulated translocation property of the protein [14].

\subsection{Hinge region}

PKC family has the hinge region, which links regulatory domain and catalytic domain, and most types, except atypical $\lambda$ and $\mathrm{l}$, contain the caspase cleavage site (Figure 1) [5]. PKC $\delta$ is essential in regulating cell apoptosis under various stimuli, and an important mechanism for the kinase is the cleavage induced by caspase 3 [15]. The cleavage will release a catalytic fragment (PKC $8 \mathrm{CF})$, which plays an important role in activation and nucleal translocation. $\mathrm{PKC} \delta$ has an autoinhibitory mechanism regulated by $\mathrm{C} 2$ domain, but caspase cleavage can separate PKC $\delta \mathrm{CF}$ from regulatory domain and kinase $\delta$ can escape from autoinhibition to get fully activated [16].

Caspase 3 cleaves the hinge region at $\mathrm{D}_{324} \mathrm{IPD}_{327}$ between Y-311 and 332 residues [15]. The phosphorylation at Y-332 has been proved the role in facilitating caspase dependent cleavage of PKC $\delta$ [17]. Also, the lower cleavage activity is detectable in PKC $\delta$ Y-332 mutant [15]. Importantly, Y-332 mutation also affects the sensitivity of tumors to cancer therapies. Lu et al utilized the mutation of Y-332 to phenylalanine (F) to test the alteration of cleavage property, founding that in cells which were treated by cisplatin, the Y332F mutant decreased the level of caspase-dependent cleavage and apoptotic effect of cisplatin treatment [15]. Hence, in gastric cancer, mutation occurred in tyrosine site inhibits not only the cleavage of $\mathrm{PKC} \delta$, but also the effect of tumor treatment.

\subsection{Kinase domain}

The catalysis is essential for PKC activation and function, and in cancer cells, another possible mutation occurs on 
the kinase domain, which could disrupt the catalytic function. In the activation mechanism of $\mathrm{PKC} \delta$, the interaction between regulatory and catalytic moiety is important. For instance, phosphorylation of tyrosine 313 located in C2 domain indirectly alters PKC enzyme activity by inhibiting phosphorylating Ser359 in the ATP positioning loop of kinase domain [18].

To get activated, the phosphorylation of the activation loop located on the $\mathrm{COOH}$-terminal of the kinase core is essential (Figure 2A). All PKCs have two conserved regions termed DFG (D-Aspartic acid, F-Phenylalanine, G-Glycine) (PKC $\zeta$ and $\imath$ are DYG) and APE (A-Alanine, P-Proline, E-Glutamic acid) motif on the activation loop, which could regulate the kinase catalytic activity. The activation loop starts from the DFG motif and end up with the APE motif, and within the loop, the phosphorylation site is a threonine residue (Figure 2B) $[19,20]$.

DFG motif also called magnesium positioning loop locates on the N-terminal of the activation loop, and various confirmation of this motif could control the kinase activity [20]. 'DFG-in' mode is an active structure, and in this mode, the phenylalanine (Phe) of DFG will sit in a hydrophobic pocket and aspartic acid (Asp) can bind the $\mathrm{Mg}^{2+}$ that interacts with ATP. 'DFG-out' represents an inactive form. Phe will occupy the ATP binding pocket rather the hydrophobic pocket, and Asp moves out of the active site and cannot interact with $\mathrm{Mg}^{2+}$, blocking ATP binding and protein catalysis [20]. APE motif is also important for the protein catalytic activity. Because in the active structure, activation loop is required to remain a stable connection with the F-helix, and APE motif is responsible for connecting the loop to the helix [21]. In gastric cancer, DFG and APE motif may be mutation sites which can lead to LOF. As Newton identified that both motifs could be mutated to disrupt the protein catalysis, causing a LOF mutation in the kinase domain [22].

Furthermore, PKC $\delta$ can still exhibit the function without the phosphorylation of threonine on the activation loop. As shown in Figure 2B, only $\mathrm{PKC} \delta$ contains two Phe (Phe 498 and Phe 525) within and after the activation loop. Liu et al. explained that these Phe residues could keep PKC $\delta$ function even under the dephosphorylation of activation loop, and mutation of either Phe decreased the function dramatically [21].

Except these potential residues, some mutation sites have been identified in gastric cancer cells. As list in Table 1, the current clinical database includes various mutation sites located in the catalytic domain of PKC $\delta$ in stomach cancer cells. The frequency of mutation was quite low, and only few samples were detected mutations. But mutated samples exhibited lower expression level (Figure 3), hence, these mutation sites could inhibit the level of PKC $\delta$ in gastric cancer cells [11].

Overall, LOF mutation is detectable in all domains of PKC $\delta$ (Table 2). Gastric cancer cause functional loss of PKC $\delta$ commonly through similarly ways in various domains, inhibiting binding of activation substrates and preventing phosphorylation of specific residues, indirectly affecting activation and catalysis of kinase.

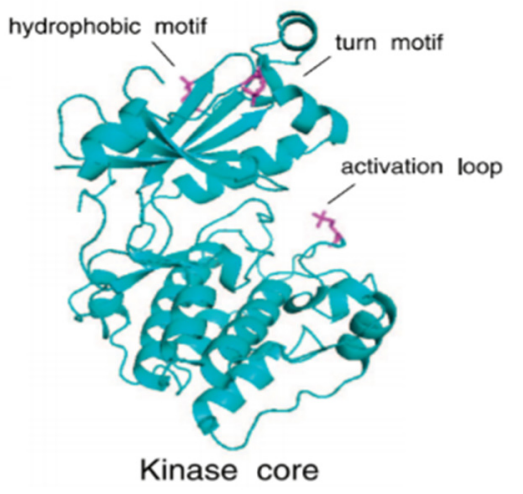

A

Activation 1oop I

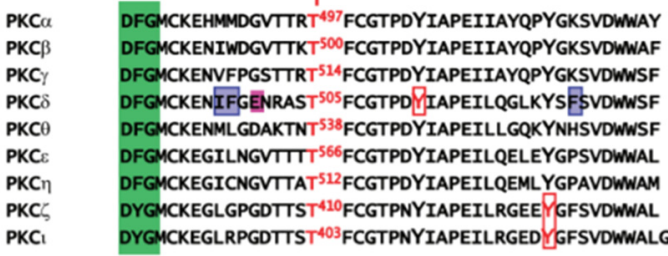

B

Figure 2. (A) The crystal structure of the kinase domain of PKC. (B) Amino sequences of the activation loop. Green color indicates the magnesium positioning loop (DFG or DYG), Red color is the Phosphorylation site of the activation loop. Also, only $\delta$ type contains two Phe (498 and 525) residues (Purple)

[19].

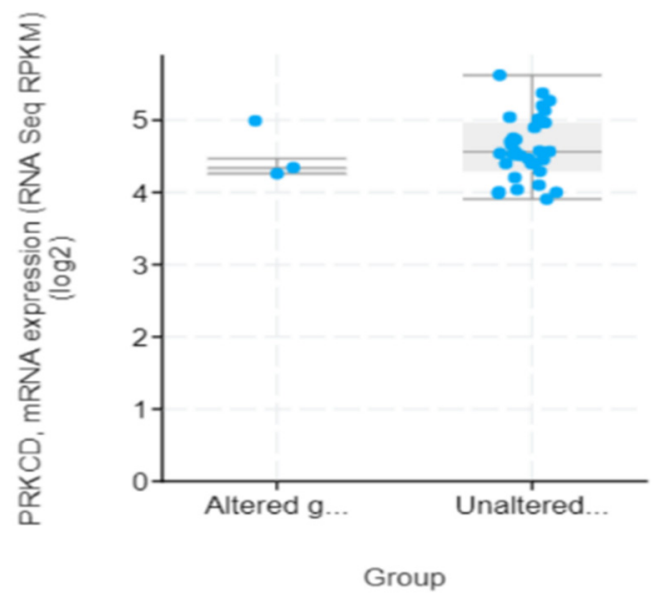

Figure 3. Comparing the expression level of PKC $\delta$ between altered and unaltered samples. All data were collected from cBioPortal. The log ratio of the test was -0.08 . If log ratio is not greater than 0 , unaltered group had higher expression level [11].

Table 1. Identified mutated sites on the catalytic domain.

\begin{tabular}{|c|c|c|c|}
\hline Location & $\begin{array}{c}\text { Normal } \\
\text { sequence }\end{array}$ & Mutant & $\begin{array}{c}\text { Mutation } \\
\text { type }\end{array}$ \\
\hline 400 & Valine (V) & $\begin{array}{c}\text { Methionine } \\
(\mathrm{M})\end{array}$ & Missense \\
\hline 431 & $\begin{array}{c}\text { Asparagine } \\
(\mathrm{N})\end{array}$ & Serine (S) & Missense \\
\hline 488 & Lysine (K) & $\begin{array}{c}\text { Asparagine } \\
(\mathrm{N})\end{array}$ & Missense \\
\hline 520 & Leucine (L) & Isoleucine (I) & Missense \\
\hline 628 & Arginine (R) & Lysine (K) & Missense \\
\hline
\end{tabular}


Table 2. All potential mutation sites of $\mathrm{PKC} \delta$.

\begin{tabular}{|c|c|}
\hline & Mutation sites \\
\hline $\begin{array}{c}\text { Regulatory domain - } \\
\text { C1 }\end{array}$ & $\begin{array}{c}\text { Binding groove and zinc finger } \\
\text { Tyrosine } 64 \\
\text { Tyrosine } 155\end{array}$ \\
\hline Hinge region & Tyrosine 332 \\
& Caspase-3 cleavage site \\
\hline \multirow{2}{*}{ Kinase domain } & DFG motif \\
& APE motif \\
& Phenylalanine 498 \\
& Phenylalanine 525 \\
\hline
\end{tabular}

\section{The effect of PKC $\delta$ LOF mutation on the p53}

$\mathrm{PKC} \delta$ is involved in various cellular pathways, such as survival, migration and apoptosis. For cancers, the more important function of $\mathrm{PKC} \delta$ is regulating the apoptosis, which mainly relies on the downstream protein, p53.

$\mathrm{PKC} \delta$ is mutated in many cases of gastric cancer, and most cases are LOF mutation. Although PKC $\delta$ has been identified as the tumor suppressor, various researches and clinical data clarifies that the mutation of PKC $\delta$ is not the main cause of tumors.

Antal et al. [1] revealed that in the tumor progression, PKC family mutation were the co-factor of other major proteins, such as p53. Perletti et al examined that cancer samples with overexpressed $\mathrm{PKC} \delta$ but downregulated p53 did not show a decrease of tumorigenicity. However, under the normal or higher level of p53, overexpression of $\mathrm{PKC} \delta$ induced significant phenotype changes for samples, indicating that $\mathrm{PKC} \delta$ could alter tumor progression but requiring the existence of p53 [23]. Furthermore, from the clinical data, the mutation of PKC $\delta$ will not decrease the survival rate of gastric cancer. As shown in Table $3 \mathrm{~A}$, the death rate for wild $\mathrm{PKC} \delta$ sample is around $78 \%$ percent, lower than the mutation group, indicating that mutation does not promote the progression of cancer. In comparison, p53 mutation decrease the survival rate by around 9 per cent (Table 3B). Hence, based on the current research and data, $\mathrm{PKC} \delta$ is the co-drive of p53 in stomach cancer.

Table 3. Survival rate for $\mathrm{PKC} \delta$ and $\mathrm{p} 53$ comparing wild type with mutation sample. All data were collected from cBioPortal [11]. (A) Survival condition of PKC $\delta$ mutation was around 80 per cent and wild type was around 78 per cent. (B) Survival condition of p53 mutation was 72 per cent, and the wild type was 81 per cent.

\begin{tabular}{|l|l|l|l|}
\hline A (PKCס) & Mutated & Wild type & Not profiled \\
\hline $\begin{array}{l}\text { 0: Alive or Dead } \\
\text { tumor free }\end{array}$ & 77 & 7598 & 248 \\
\hline $\begin{array}{l}\text { 1: Dead with } \\
\text { tumor }\end{array}$ & 19 & 2177 & 261 \\
\hline Survival rate & $80 \%$ & $78 \%$ & \\
\hline
\end{tabular}

\begin{tabular}{|l|l|l|l|}
\hline B (p53) & Mutated & Wild type & Not profiled \\
\hline $\begin{array}{l}\text { 0: Alive or Dead } \\
\text { tumor free }\end{array}$ & 2621 & 5054 & 248 \\
\hline $\begin{array}{l}\text { 1: Dead with } \\
\text { tumor }\end{array}$ & 1007 & 1189 & 261 \\
\hline Survival rate & $72 \%$ & $81 \%$ & \\
\hline
\end{tabular}

\subsection{Inhibiting transcription of p53}

The evidence indicates that tumor promoting substance, such as phorbol ester, does not directly down regulate p53. Instead, they will inhibit $\mathrm{PKC} \delta$ to affect the expression of p53. Notably, down-regulation of p53 is caused by preventing the transcription rather than increasing degradation [24].

Bcl-2-associated transcription factor 1 (Btf) is the transcription factor involved in the p53-dependent apoptosis, and the evidence show that Btf also correlates with PKC $\delta$ [25]. In the normal transcription process of p53, upon DNA damage, PKC $\delta$ will form a complex with Btf, following by the complex co-occupy the core promoter element of p53 (p53CPE) to induce p53 gene transcription (Figure 4) [25].

Moreover, the interaction between $\mathrm{PKC} \delta$ and $\mathrm{Btf}$ is related to the activity of $\mathrm{PKC} \delta$. Hanshao et al. identified that blocking the activity of $\mathrm{PKC} \delta$ decreased the binding affinity of Btf and inhibited interaction with p53CPE [25]. The activity of $\mathrm{PKC} \delta$ is highly related to the phosphorylation of various sites, and as known, phosphorylation can change the protein folding and structure. So, the phosphorylation of specific sites can alter the structure of $\mathrm{PKC} \delta$, creating the specific structure for the binding of Btf and p53CPE. Also, Btf is the Bcl-2 family protein, and this family will bind to the $\mathrm{C} 1$ domain of PKC [26]. As described before, LOF mutation in $\mathrm{C} 1$ domain, such as sites around binding groove and zinc finger, inhibits the binding of substrates and the phosphorylation of proteins. Therefore, PKC $\delta \mathrm{C} 1 \mathrm{LOF}$ mutants affect the phosphorylation process, causing no suitable structure for binding to Btf and p53, inhibiting the transcription of $\mathrm{p} 53$.

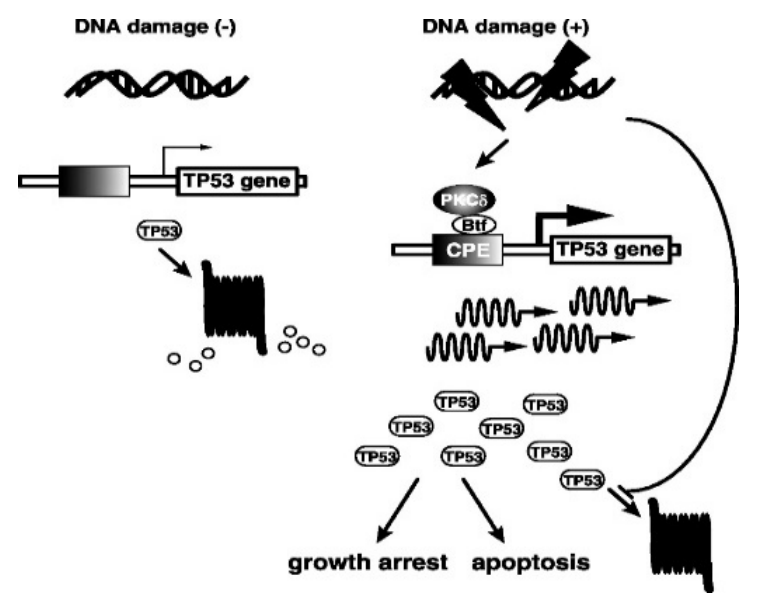

Figure 4. Transcription process of p53 mediated by Btf and $\mathrm{PKC} \delta$ [25].

\subsection{Affecting the nuclear accumulation of p53}

In cancer cells, in response to various stress, p53 need to translocate into nucleus to induce apoptosis. For the p53 nucleus accumulation, $\mathrm{PKC} \delta$ is a crucial element that can mediate this process. Abbas et al. identified that the suppression of p53 translocating to nucleus were not caused by the change of p53 shuttling properties. In contrast, in cells which deleted $\mathrm{PKC} \delta$ or were treated by 
rottlerin which was a $\mathrm{PKC} \delta$ inhibitor, p53 level in nucleus exhibited the detectable reduction, which could prove that $\mathrm{PKC} \delta$ is essential for the relocation process of p53 [24]. So, there is a probability that PKC $\delta$ LOF mutation will affect the accumulation of $\mathrm{p} 53$. The reduction of nuclear p53 may due to degradation of p53 mediated by Mouse double minute 2 homolog (MDM2) as $\mathrm{PKC} \delta$ is critical in inhibiting degradation.

In normal cells, p53 is unstable and remains a low level because of the degradation pathway regulated by MDM2 in both cytoplasm and nucleus (Figure 5) [27]. But under various cellular stress, p53 can be phosphorylated at Ser15 to against the binding of MDM2, stopping the degradation and increasing nucleus accumulation [27]. Ser15 phosphorylation is associated with PKC $\delta$ but depends on the activation of kinase. Lee et al. utilized sodium nitroprusside (SNP) to activate PKC $\delta$. causing phosphorylating Ser15 of p53, inhibiting the MDM2-dependent protein degradation and increasing p53 stability. However, after adding PKC $\delta$ inhibitor, the phosphorylation was decreased [28]. PKC $\delta$ LOF mutation can occur in both regulatory and catalytic domain, and all these mutations can inhibit the activation and function of PKC $\delta$. Hence, based on the current findings, it is conceivable that $\mathrm{PKC} \delta$ LOF mutants cannot induce Ser15 phosphorylation, leading to increased MDM2-dependent degradation.

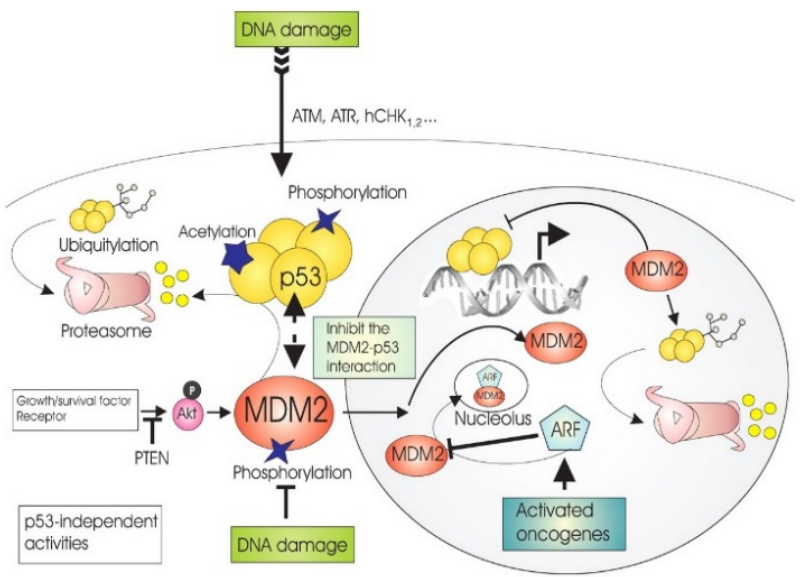

Figure 5. Degradation pathway mediated by MDM2 [27].

\subsection{Reducing the apoptotic effect by inhibiting the Ser46 phosphorylation of p53}

The phosphorylation of Ser46 is a primary and critical determinant for the apoptotic effect of p53 and can induce the activation of downstream proapoptotic gene of p53, such as actin-interacting protein 1 (AIP1) [29]. p53-dependent induced nuclear protein 1 (p53DINP1) is the key element involved in the apoptotic pathway induced by $\mathrm{p} 53$ and responsible for the recruitment of p53 kinase, such as PKC $\delta$, to phosphorylate Ser46 [30].

Furthermore, Ser46 phosphorylation required the cleavage of $\mathrm{PKC} \delta$. In response to the stress, $\mathrm{PKC} \delta$ will be cleaved by caspase and release PKC $\delta C F$. The analysis of interaction between p53 and PKC $\delta$ reveals that p53 binds to $\mathrm{PKC} \delta \mathrm{CF}$ rather than regulatory fragment [10]. However, $\mathrm{PKC} \delta$ mutation may affect caspase-dependent cleavage process. The phosphorylation of tyrosine residue, Y-332, located in the hinge region is responsible for regulating the cleavage of $\mathrm{PKC} \delta$. The mutation of Y-332 reduces the cleavage activity, inhibiting the release of $\mathrm{PKC} \delta \mathrm{CF}$, leading to the reduction of apoptosis induced by $\mathrm{p} 53$.

After induction of cellular stresses, activated $\mathrm{PKC} \delta$ go into nucleus and interact with p53. Also, caspase 3 is translocated to nucleus, indicating that the accumulation happens before cleavage [31]. Hence, nuclear accumulation of $\mathrm{PKC} \delta$ is critical for the cleavage and interaction with p53. As mentioned, Y-64 and -155 residues in regulatory domain have been identified their role in regulating translocation of $\mathrm{PKC} \delta$, and their mutation can inhibit the nuclear accumulation [14]. Hence, LOF mutation has probability to affect the apoptotic function of $\mathrm{p} 53$ by inhibiting nuclear localization of PKC $\delta$.

In sum, PKC $\delta$ affects function of p53 through various pathways. All possible effects and mechanisms are listed in Table 4, and related mutated residues are in throughout domains of $\mathrm{PKC} \delta$. However, association sites of PKC $\delta$ with some proteins, such as Btf, have not been identified. So, it is essential to conduct structural analysis to investigate interaction residues.

Table 4. Effects of PKC $\delta$ LOF mutants on p53 and possible related mutation residues and mechanisms.

\begin{tabular}{|c|c|c|c|}
\hline Effect on p53 & $\begin{array}{c}\text { Domai } \\
\text { of } \\
\text { PKC } \delta \\
\end{array}$ & $\begin{array}{c}\text { Related } \\
\text { mutation } \\
\text { sites } \\
\end{array}$ & $\begin{array}{c}\text { Mechanism of } \\
\text { mutants affect } \\
\text { p53 }\end{array}$ \\
\hline $\begin{array}{c}\text { Inhibiting } \\
\text { transcription } \\
\text { of p53 } \\
\end{array}$ & $\mathrm{C} 1$ & $\begin{array}{l}\text { Binding } \\
\text { groove and } \\
\text { zinc finger }\end{array}$ & $\begin{array}{c}\text { Reducing } \\
\text { binding affinity } \\
\text { of Btf }\end{array}$ \\
\hline \multirow[t]{2}{*}{$\begin{array}{l}\text { Affecting the } \\
\text { nuclear } \\
\text { accumulation } \\
\text { of p53 }\end{array}$} & $\begin{array}{l}\text { Regulat } \\
\text { ory } \\
\text { domain }\end{array}$ & \multirow[t]{2}{*}{$\begin{array}{l}\text { Residues } \\
\text { that inhibit } \\
\text { activation of } \\
\text { PKC } \delta\end{array}$} & \multirow[t]{2}{*}{$\begin{array}{l}\text { Increasing } \\
\text { MDM2 } \\
\text { mediated } \\
\text { degradation of } \\
\text { nuclear and } \\
\text { cytoplasmic } \\
\text { p53 }\end{array}$} \\
\hline & $\begin{array}{l}\text { Kinase } \\
\text { domain }\end{array}$ & & \\
\hline \multirow[t]{2}{*}{$\begin{array}{l}\text { Reducing the } \\
\text { apoptotic } \\
\text { effect of p53 }\end{array}$} & $\begin{array}{l}\text { Hinge } \\
\text { region }\end{array}$ & $\begin{array}{c}\text { Caspase- } 3 \\
\text { cleavage } \\
\text { site or } \\
\text { Tyrosine } \\
332\end{array}$ & $\begin{array}{c}\text { Inhibiting } \\
\text { caspase } 3 \\
\text { induced } \\
\text { cleavage, } \\
\text { reducing } \\
\text { phosphorylatio } \\
\text { n of p53 on Ser } \\
46 \\
\end{array}$ \\
\hline & $\begin{array}{l}\text { Regulat } \\
\text { ory } \\
\text { domain }\end{array}$ & $\begin{array}{c}\text { Tyrosine } 64 \\
\text { or } 155\end{array}$ & $\begin{array}{c}\text { Inhibiting } \\
\text { nuclear } \\
\text { accumulation } \\
\text { of PKC } \delta, \\
\text { reducing } \\
\text { cleavage }\end{array}$ \\
\hline
\end{tabular}

\section{Disrruption of tight junction formation by PKC $\delta$ LOF mutation}

Tight junctions (TJs) are important intracellular 
complexes that build a selective barrier between cells [32]. TJs are composed of various proteins, including transmembrane proteins (occludin (OCLN), claudin family (CLDN), junctional adh

esion molecules (JAM)), plaque proteins (zonula occludens (ZO)-1,2,3) and other regulatory proteins [33]. In cancers, the progression of metastasis requires to interrupt adhesion capacity between cells, providing conditions for cancer cells to dissociate from the original tumor site and invade surrounding tissues[34]. Therefore, TJs are the first step that tumor cells need to disrupt to metastasis.

Within TJ proteins, PKC $\delta$ has been identified the role of regulation on ZO-1 [35], which are correlated with the progression with gastric cancer [36].

ZO proteins (ZO-1, -2 and -3), an important protein family in TJs, regulates the correct assemble of the barrier and responsible for connecting other TJ proteins. To form cell barriers, transmembrane proteins are necessary components, but they only accumulate in membrane and cannot form strands [37, 38]. Structural analysis reveals that $\mathrm{ZO}$ proteins have a $\mathrm{N}$-terminal fragment, containing three 3 PSD-95/discs-large/Zonula occludens-1 (PDZ) domains and ZO unique motifs (U5, U6 and GUK), which can interact with known TJ transmembrane proteins, such as PDZ domains bind CLDN and JAM, and unique motifs interact with OCLN, indicating that $\mathrm{ZO}$ protein links other proteins in TJs (Figure 6) [38, 39]. Umeda et al. identified that ZO-1 deficient cells could not detect assembled TJs. However, after introducing exogenous ZO-1, claudins were polymerized into strands and $\mathrm{TJ} s$ formation was recovered [37]. Hence, ZO-1 is important in assembling $\mathrm{TJ}$ proteins to form the barrier.

Within cells, ZO proteins are dynamic and translocate between the TJs and the cytoplasmic pool. PKC $\delta$ is identified to promote membrane assemble of ZO-1. Cario et al. revealed that in intestinal epithelia cells, the activation of PKC $\delta$ was related to increased barrier function through localization of ZO-1. Transepithelial resistance (TER) was the measurement of function and permeability of TJs. In PKC $\delta$ activation cells, comparing with inactivation cells or treated with $\mathrm{PKC}$ inhibitor, a higher TER was detected, accompanied by ZO-1 translocated to further TJs areas to form more solid lateral contacts between cells [40]. Hence, PKC $\delta$ can regulate redistribution of ZO-1 and the process strongly depends on kinase activation. The mechanism of how PKC $\delta$ regulate ZO-1 is unknown, but based on current research, PKC $\delta$ may interact with mutliple domain of ZO-1 to regulate translocation. ZO-1 contains a conserved region (Figure 6), SH3-GUK, which has various functions, such as contacting with transcription factors and TJ proteins [39]. Fanning et al. proved that U5 and GUK were critical in locating ZO-1 to TJs, but U6 inhibited the translocation process [41]. Hence, it is inferable that PKC $\delta$ may interact with U5 and GUK but inhibit U6 function to promote translocation of ZO-1.

In gastric cancer, the common mutation type for $\mathrm{PKC} \delta$ is LOF. If mutation occurs on specific residues in various domains, such as $\mathrm{C} 1$ domain, $\mathrm{PKC} \delta$ cannot be activated. For instance, mutations around binding groove and zinc finger located in $\mathrm{C} 1$ domain prevent the binding of DAG, inhibiting activation of PKC $\delta$. The translocation of ZO-1 is dependent on activated $\mathrm{PKC} \delta$, so inactivated state cannot relocate $\mathrm{ZO}-1$ to $\mathrm{TJ}$, resulting in the disruption of the formation of TJs and tumor cells can invade surrounding cells. Also, lack of ZO-1 in TJs increase a nuclear compound which can regulate proliferation, named ZO-1-associated nucleic acid-binding protein (ZONAB) or DNA-binding Protein A (DbpA), leading to tumor becomes more aggressive.

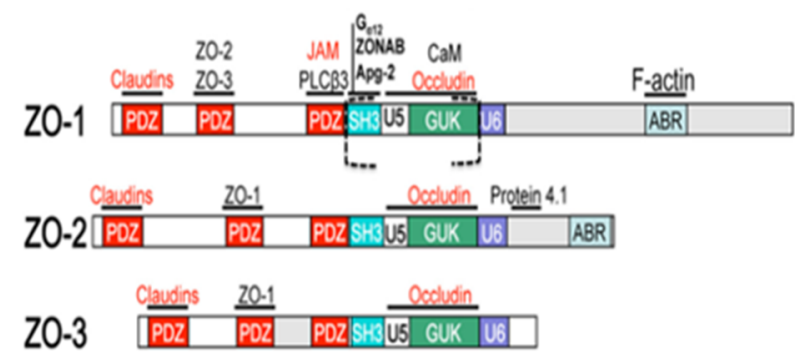

Figure 6. Structure of $\mathrm{ZO}$ proteins [39]. ZO proteins share similar $\mathrm{N}$-terminal domain, including $\mathrm{PDZ}, \mathrm{SH} 3$, unique (U5,GUK, U6) motif. First and third PDZ motifs bind to claudins and JAM, and the second PDZ link ZO proteins together. All ZO proteins contain a conserved region, SH3-U6.

$\mathrm{SH} 3$ domain is responsible for the binding to transcription factors, such as ZONAB. GUK together with U5 regulate the binding of occluding and direct ZO to TJs. U6 reduce binding affinity of occluding and inhibit translocation process.

\section{Discussion}

In gastric cancer, although $\mathrm{PKC} \delta$ isoform is a suppressor and involved in various pathways, such as mediate apoptotic pathway and inhibiting abnormal proliferation and metastasis, increased cancer progression is not mainly due to mutation of PKC $\delta$ alone, instead of, the effect of the mutation on downstream protein, p53, or cellular components, tight junction. Therefore, the function of PKC $\delta$ in cancer cells highly relies on downstream proteins. PKC $\delta$, except tumor suppressor, can also enhance growth of tumor in some cancer types through inducing expression or activation of downstream proteins correlated with tumorigenicity. Cell type- and downstream protein- dependent regulator

PKC $\delta$ has emerged as a novel regulator of progression of pancreatic cancer, but the regulation is promoting tumor rather than suppressing. In ductal pancreatic carcinoma cells, $\mathrm{PKC} \delta$ is overexpressed comparing with normal tissues. Also, PKC $\delta$ induces the expression of phosphatidylinositol-3-kinase (PI3K), a molecule regulating cancer progression, and extracellular receptor kinase (ERK), an essential compound in the mitogenic pathway. The overexpression of $\mathrm{PKC} \delta$ together with PI3k and ERK significantly increases growth of cancer cells in a anchorage-independent manner, which is a hallmark of carcinoma [42]. In pancreatic cancer, an important tumor promoting protein, Signal transducer and activator of transcription 3 (STAT3), which regulate invasion and survival or death of cancer cells, also requires PKC $\delta$. From the research, 
PKC $\delta$ phosphorylates STAT3 at Tyrosine 705, enhancing activation of STAT3, leading to survival and invasion of tumor cells [43]. Hence, PKC $\delta$ exhibits a complex role in tumor progression based on cell types and interaction with downstream proteins. Importantly, therapies targeting PKC $\delta$ is varied using in different cancers.

Although there are various inhibitors, such as rottlerin and PKC-412, designed for PKC, current approved inhibitors target different $\mathrm{PKC}$ proteins and not specific for PKC $\delta$ (Table 5). Treatment of gastric cancer using these inhibitors is effective, but they may act in a PKC $\delta$-independent manner. For instance, Song et al. proved that rottlerin promoted apoptosis of stomach cancer cell lines. However, tumor inhibition by rottlerin maybe not through suppressing PKC $\delta$ activity [44]. Hence, if specifically taking $\mathrm{PKC} \delta$ as a gastric cancer therapy target, $\delta$ activators are appropriate. As the role of $\mathrm{PKC}$ in gastric cell is a suppressor, which engages in apoptotic pathway induced by $\mathrm{p} 53$ and assemble of tight junctions. Ingenol, a PKC $\delta$ activator, is emerged as an antitumor agent and utilized in skin cancer (91). However, it is not known whether ingenol is also useful in gastric cancer. Also, LOF mutation may cause failure in activator treatment.

Table 5. Information of various inhibitors targeting PKC family.

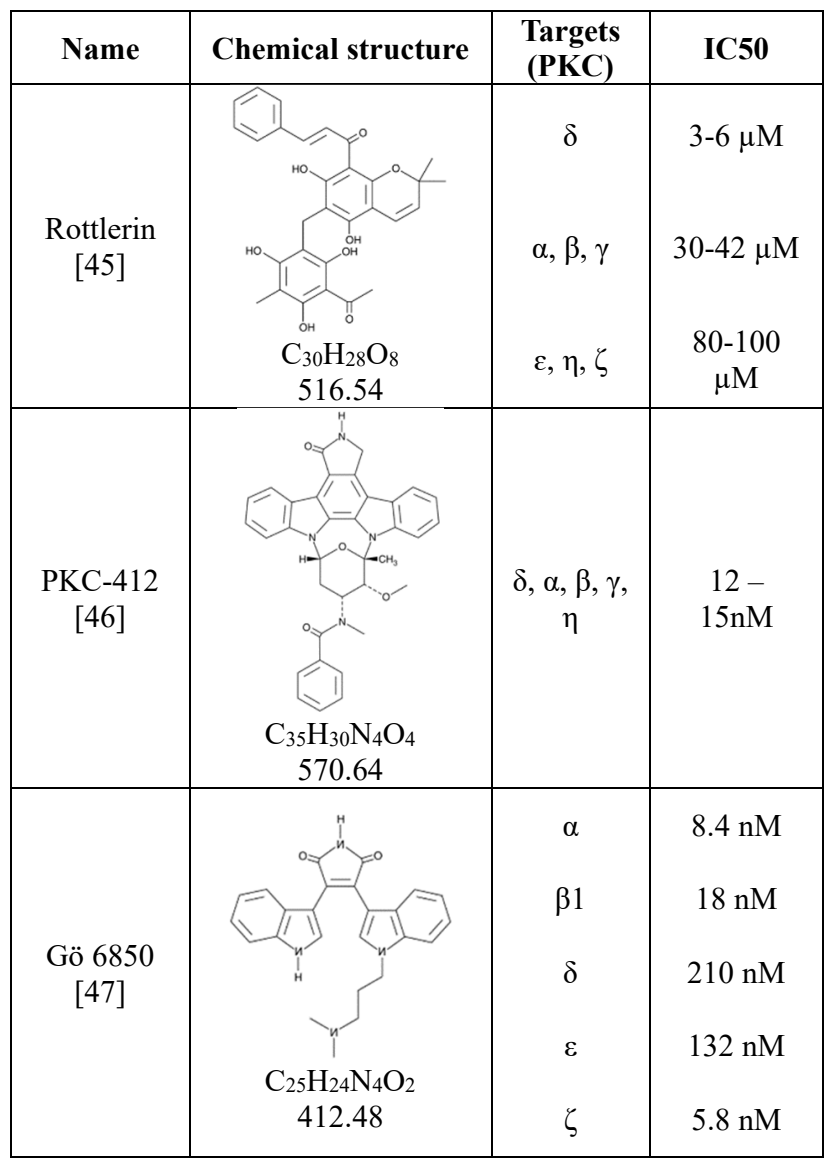

Moreover, chemotherapy agents used for tumors not only inhibit $\mathrm{PKC} \delta$ but also engage in other pathways induced by other PKC proteins. For instance, resveratrol is a chemotherapy agent due to its properties in inhibiting tumor growth. In stomach cancer cells, resveratrol promotes apoptotic pathway involved p53 and inhibits $\mathrm{PKC} \delta$ level, but meantime, PKC $\alpha$ will be increased [48]. Also, resveratrol only affects membrane associated PKC $\delta$ level, not inhibits cytosolic protein pool, which may not affect the regulation of $\mathrm{p} 53$ by $\mathrm{PKC} \delta$ as $\mathrm{p} 53$ requires cytosolic and nuclear PKC $\delta$ [48]. Hence, inhibitors treat gastric cancer may through regulating other $\mathrm{PKC}$ proteins.

Considering mechanisms of PKC inhibitors or chemotherapy agents, there is a potential treatment strategy for gastric cancer involving $\mathrm{PKC} \delta$, combining tumor-suppressor gene therapy with chemotherapy medication. Tumor-suppressor gene therapy is functioning through delivering therapeutic genes to targeted cells to prevent growth of tumor cells. For instance, delivering p53, a well-known tumor suppressor, to cancer cells to restore mutated or functionally inactivated p53 [49]. Clinical studies reveal that p53 gene therapy is well tolerated and no significant side effects on patients. So PKC $\delta$ gene therapy has the possible to restore LOF mutation and inhibits gastric cancer. But in gene therapy, a problem is that some cancer cells can resume growing due to instable genes [49]. Chemotherapy agents inhibit cancer cell properties by interacting with tumor suppressor proteins, hence, it is conceivable that gene therapy, if combining with chemotherapies, can increase sensitivity and response of cancer cells to medications.

\section{Conclusion}

PKC $\delta$ is involved in several pathways related to proliferation or apoptosis, and the disruption of these regulations cause the progression of gastric cancer. Some findings identified that $\mathrm{PKC} \delta$ is mutated in gastric cancer, and the most common type is LOF mutation. PKC $\delta$ is composed of two moieties, including regulatory $(\mathrm{C} 1$ and C2) and kinase domain, and mutation occurred throughout these domains, inhibiting activation, cleavage, and translocation of PKC $\delta$. Furthermore, mutation of PKC $\delta$ also affects p53 dependent apoptotic pathway and the formation of tight junctions.

\section{Reference}

1. Corina e. Antal, Andrew m. Hudson, E. Kang, C. Zanca, C. Wirth, Natalie 1. Stephenson, et al. Cancer-Associated Protein Kinase C Mutations Reveal Kinase's Role as Tumor Suppressor. Cell (Cambridge). 160(3):489-502 (2015)

2. M. Cooke, A. Magimaidas, V. Casado-Medrano, M.G. Kazanietz. Protein kinase C in cancer: The top five unanswered questions. Molecular carcinogenesis. 56(6):1531-42 (2017)

3. R. Garg, L.G. Benedetti, M.B. Abera, H. Wang, M. Abba, M.G. Kazanietz. Protein kinase $\mathrm{C}$ and cancer: what we know and what we do not. Oncogene. 33(11) (2013)

4. A.C. Newton. Protein kinase C: structure, function, 
and regulation. The Journal of biological chemistry. 270(48):28495-8 (1995)

5. C. Giorgi, C. Agnoletto, C. Baldini, A. Bononi, M. Bonora, S. Marchi, et al. Redox control of protein kinase C: cell- and disease-specific aspects. Antioxidants \& redox signaling. 13(7):1051-85 (2010)

6. A.C. Newton, J. Brognard. Reversing the Paradigm: Protein Kinase $\mathrm{C}$ as a Tumor Suppressor. Trends in pharmacological sciences (Regular ed). 38(5):438-47 (2017)

7. A. Basu, D. Pal. Two faces of protein kinase $\mathrm{C} \delta$ : the contrasting roles of PKC $\delta$ in cell survival and cell death. TheScientificWorld. 10:2272-84 (2010)

8. A.S. Clark, K.A. West, P.M. Blumberg, P.A. Dennis. Altered protein kinase $\mathrm{C}$ (PKC) isoforms in non-small cell lung cancer cells: $\mathrm{PKC} \delta$ promotes cellular survival and chemotherapeutic resistance. Cancer research (Chicago, Ill). 63(4):780-6 (2003)

9. B.A. Teicher. Protein kinase $\mathrm{C}$ as a therapeutic target. Clinical cancer research. 12(18):5336-45 (2006)

10. K. Yoshida, H. Liu, Y. Miki. Protein kinase C delta regulates Ser46 phosphorylation of p53 tumor suppressor in the apoptotic response to DNA damage. The Journal of biological chemistry. 281(9):5734-40 (2006)

11. J. Gao, B.A. Aksoy, U. Dogrusoz, G. Dresdner, B. Gross, S.O. Sumer, et al. Integrative Analysis of Complex Cancer Genomics and Clinical Profiles Using the cBioPortal. Science signaling. 6(269):pl1-pl (2013)

12. G. Zhang, M.G. Kazanietz, P.M. Blumberg, J.H. Hurley. Crystal structure of the Cys2 activator-binding domain of protein kinase $\mathrm{C} \delta$ in complex with phorbol ester. Cell (Cambridge). 81(6):917-24 (1995)

13. J. Das, G.M. Rahman. C1 Domains: Structure and Ligand-Binding Properties. Chemical reviews. 114(24):12108-31 (2014)

14. M.J. Humphries, A.M. Ohm, J. Schaack, T.S. Adwan, M.E. Reyland. Tyrosine phosphorylation regulates nuclear translocation of $\mathrm{PKC} \delta$. Oncogene. 27(21):3045-53 (2008)

15. W. Lu, H.-K. Lee, C. Xiang, S. Finniss, C. Brodie. The phosphorylation of tyrosine 332 is necessary for the caspase 3-dependent cleavage of PKC $\delta$ and the regulation of cell apoptosis. Cellular signalling. 19(10):2165-73 (2007)

16. J. Gong, M. Park, S.F. Steinberg. Cleavage Alters the Molecular Determinants of Protein Kinase C- $\delta$ Catalytic Activity. Molecular and cellular biology. 37(20) (2017)

17. S.F. Steinberg. Cardiac actions of protein kinase $C$ isoforms. Physiology (Bethesda, Md). 27(3):130-9 (2012)

18. J. Gong, Y. Yao, P. Zhang, B. Udayasuryan, E.V. Komissarova, J. Chen, et al. The C2 Domain and Altered ATP-Binding Loop Phosphorylation at Ser ${ }^{359}$
Mediate the Redox-Dependent Increase in Protein Kinase C- $\delta$ Activity. Molecular and cellular biology. 35(10): 1727-40 (2015)

19. S.F. Steinberg. Structural Basis of Protein Kinase C Isoform Function. Physiological Reviews. 88(4):1341-78 (2008)

20. V. Modi, R.L. Dunbrack. Defining a new nomenclature for the structures of active and inactive kinases. Proceedings of the National Academy of Sciences - PNAS. 116(14):6818-27 (2019)

21. Y. Liu, N.V. Belkina, C. Graham, S. Shaw. Independence of protein kinase C-delta activity from activation loop phosphorylation: structural basis and altered functions in cells. The Journal of biological chemistry. 281(17):12102-11 (2006)

22. A.C. Newton. Protein kinase C: perfectly balanced. Critical reviews in biochemistry and molecular biology. 53(2):208-30 (2018)

23. G. Perletti, E. Marras, D. Dondi, D. Osti, T. Congiu, R. Ferrarese, et al. p21Waf1/Cip1 and p53 are downstream effectors of protein kinase $\mathrm{C}$ delta in tumor suppression and differentiation in human colon cancer cells. International journal of cancer. 113(1):42-53 (2005)

24. T. Abbas, D. White, L. Hui, K. Yoshida, D.A. Foster, J. Bargonetti. Inhibition of human p53 basal transcription by down-regulation of protein kinase Cdelta. The Journal of biological chemistry. 279(11):9970 (2004)

25. L. Hanshao, L. Zheng-Guang, M. Yoshio, Y. Kiyotsugu. Protein Kinase C $\delta$ Induces Transcription of the TP53 Tumor Suppressor Gene by Controlling Death-Promoting Factor Btf in the Apoptotic Response to DNA Damage. Molecular and Cellular Biology. 27(24):8480-91 (2007)

26. C.M. Barrett, F.L. Lewis, J.B. Roaten, T.W. Sweatman, M. Israel, J.L. Cleveland, et al. Novel extranuclear-targeted anthracyclines override the antiapoptotic functions of $\mathrm{Bcl}-2$ and target protein kinase C pathways to induce apoptosis. Molecular cancer therapeutics. 1(7):469-81 (2002)

27. U.M. Moll, O. Petrenko. The MDM2-p53 Interaction. Molecular Cancer Research. 1(14):1001-8 (2003)

28. S.-J. Lee, D.-C. Kim, B.-H. Choi, H. Ha, K.-T. Kim. Regulation of $\mathrm{p} 53$ by activated protein kinase C-delta during nitric oxide-induced dopaminergic cell death. The Journal of biological chemistry. 281(4):2215-24 (2006)

29. L. Feng, M. Hollstein, Y. Xu. Ser46 Phosphorylation Regulates p53-Dependent Apoptosis and Replicative Senescence. Cell cycle (Georgetown, Tex). 5(23):2812-9 (2006)

30. J. Shahbazi, R. Lock, T. Liu. Tumor Protein 53-Induced Nuclear Protein 1 Enhances p53 Function and Represses Tumorigenesis. Frontiers in genetics. 4:80- (2013)

31. K. Shinji, K. Ushio, T. Yoshihide, H. Tony. Nuclear Translocation of Caspase-3 Is Dependent on Its 
Proteolytic Activation and Recognition of a Substrate-like Protein(s). The Journal of biological chemistry. 280(2):857-60 (2005)

32. M.B. Zeisel, P. Dhawan, T.F. Baumert. Tight junction proteins in gastrointestinal and liver disease. Gut. 68(3):547-61 (2019)

33. E. Salvador, M. Burek, C.Y. Förster. Tight Junctions and the Tumor Microenvironment. Current pathobiology reports. 4(3):135-45 (2016)

34. W.G. Jiang, A.J. Sanders, M. Katoh, H. Ungefroren, F. Gieseler, M. Prince, et al. Tissue invasion and metastasis: Molecular, biological and clinical perspectives. Seminars in cancer biology. 35:S244-S75 (2015)

35. Y. James, N. Anthony, M. Joshua, C. Isabel, C.S. Jaekyung, T.W. Roger, et al. Bryostatin-1 enhances barrier function in T84 epithelia through PKC-dependent regulation of tight junction proteins. American Journal of Physiology - Cell Physiology. 285(2):300-9 (2003)

36. M.B. Resnick, M. Gavilanez, E. Newton, T. Konkin, B. Bhattacharya, D.E. Britt, et al. Claudin expression in gastric adenocarcinomas: a tissue microarray study with prognostic correlation. Human pathology. 36(8):886-92 (2005)

37. K. Umeda, J. Ikenouchi, S. Katahira-Tayama, K. Furuse, H. Sasaki, M. Nakayama, et al. ZO-1 and ZO-2 independently determine where claudins are polymerized in tight-junction strand formation. Cell (Cambridge). 126(4):751 (2006)

38. A.S. Fanning, J.M. Anderson. Zonula Occludens-1 and -2 Are Cytosolic Scaffolds That Regulate the Assembly of Cellular Junctions. Annals of the New York Academy of Sciences. 1165(1):113-20 (2009)

39. M.F. Lye, A.S. Fanning, Y. Su, J.M. Anderson, A. Lavie. Insights into regulated ligand binding sites from the structure of ZO-1 Src homology 3-guanylate kinase module. The Journal of biological chemistry. 285(18):13907-17 (2010)

40. E. Cario, G. Gerken, D.K. Podolsky. Toll-like receptor 2 enhances ZO-1-associated intestinal epithelial barrier integrity via protein kinase C. Gastroenterology (New York, NY 1943).
127(1):224-38 (2004)

41. A.S. Fanning, B.P. Little, C. Rahner, D. Utepbergenov, Z. Walther, J.M. Anderson. The unique-5 and -6 motifs of $\mathrm{ZO}-1$ regulate tight junction strand localization and scaffolding properties. Molecular biology of the cell. 18(3):721-31 (2007)

42. L.V. Mauro, V.C. Grossoni, A.J. Urtreger, C. Yang, L.L. Colombo, A. Morandi, et al. PKC Delta (PKCdelta) promotes tumoral progression of human ductal pancreatic cancer. Pancreas. 39(1):e31-e41 (2010)

43. G.P. Sorescu, L.W. Forman, D.V. Faller. Effect of inhibition of protein kinase $\mathrm{C}$ delta $(\mathrm{PKC} \delta)$ on pancreatic cancer cells. Journal of clinical oncology. 30(15_suppl):e14591-e (2012)

44. J. Song, Y. Zhou, Y. Gong, H. Liu, L. Tang. Rottlerin promotes autophagy and apoptosis in gastric cancer cell lines. Molecular medicine reports. 18(3):2905-13 (2018)

45. S.P. Davies, H. Reddy, M. Caivano, P. Cohen. Specificity and mechanism of action of some commonly used protein kinase inhibitors. Biochemical journal. 351(Pt 1):95-105 (2000)

46. D. Fabbro, E. Buchdunger, J. Wood, J. Mestan, F. Hofmann, S. Ferrari, et al. Inhibitors of Protein Kinases: CGP 41251, a Protein Kinase Inhibitor with Potential as an Anticancer Agent. Pharmacology \& therapeutics (Oxford). 82(2):293-301 (1999)

47. D. Toullec, P. Pianetti, H. Coste, P. Bellevergue, T. Grand-Perret, M. Ajakane, et al. The bisindolylmaleimide GF $109203 \mathrm{X}$ is a potent and selective inhibitor of protein kinase C. The Journal of biological chemistry. 266(24):15771-81 (1991)

48. M.J. Atten, E. Godoy-Romero, B.M. Attar, T. Milson, M. Zopel, O. Holian. Resveratrol regulates cellular PKC $\alpha$ and $\delta$ to inhibit growth and induce apoptosis in gastric cancer cells. Investigational new drugs. 23(2):111-9 (2005)

49. V.V. Ternovoi, D.T. Curiel, B.F. Smith, G.P. Siegal. Adenovirus-mediated p53 tumor suppressor gene therapy of osteosarcoma. Laboratory investigation. 86(8):748-66 (2006) 